\title{
Optimized health parameters using PSO: a cost effective RFID based wearable gadget with less false alarm rate
}

\author{
Talha Ahmed Khan', Muhammad Alam², M. Junaid Tahir ${ }^{3}$, Kushsairy Kadir ${ }^{4}$, Zeeshan Shahid ${ }^{5}$, \\ M.S Mazliham ${ }^{6}$ \\ 1,2,3,4 British Malaysian Institute, Universiti Kuala Lumpur, Malaysia \\ ${ }^{1}$ Usman Institute of Technology, Pakistan \\ ${ }^{6}$ Malaysian Institute of Information Technology Universiti Kuala Lumpur, Kuala Lumpur, Malaysia \\ ${ }^{2}$ Ilma University, Karachi, Pakistan \\ ${ }^{5}$ Institute of Business Management (IoBM), Karachi, Pakistan
}

\begin{tabular}{l} 
Article Info \\
\hline Article history: \\
Received Oct 1, 2018 \\
Revised Dec 10, 2018 \\
Accepted Jan 25, 2019 \\
\hline
\end{tabular}

\section{Keywords:}

Body temperature

Cardiac arrhythmia

Health care

Patient location

RFID

\begin{abstract}
The motive of contriving the proposed research was originated after recognizing some false alarm in measuring health parameters and practical issues in hospitals for example approachability and presence of patient at designated place for the evaluation of the health parameters like Blood pressure, sugar, body temperature, pulse and some other parameters. The manual entry of the data into the systems have been become a critical problem. To vanquish this problem, a wearable gadget has been designed, so that a patient can carry it feasibly. Various approaches like Bayesian classifier have been applied to minimize the false alarm. Fuzzy logic, Kalman filtering, extended Kalman filtering, support vector machine, multilayer perceptron, adaptive neuro fuzzy inference system and cuckoo search have been applied to eliminate the false alarm and give the best optimum solution. Results have proved that PSO worked betted as its convergence time is less than the others algorithms and produced best optimum value for the body vitals. Moreover, PSO has been applied to achieve the best optimal results and to increase the performance. Monitoring of heart pulse rate and body temperature readings that were recorded in database were then tested and validated by comparing digital thermometer and digital inflator. PSO will converge and give the global best position of data by updating the velocity. Results proved that PSO produced better results by optimizing with better accuracy and precision and can be acknowledged as cost-effective solution.
\end{abstract}

Copyright $@ 2019$ Institute of Advanced Engineering and Science. All rights reserved.

\section{Corresponding Author:}

Muhammad Mansoor Alam,

Malaysian Institute of Information Technology Universiti Kuala Lumpur,

Kuala Lumpur, Malaysia.

Email: mansoor@unikl.edu.my

\section{INTRODUCTION}

High ratio of false alarm in measurement equipment of body vitals leads towards the wrong diagnosis which may cause several casualties in hospitals. An inaccurate observation disturbs the patients' health not only but also creates a negative impact for the hospital management as well [1]. High false alarm in measuring body vitals lead towards the poor diagnosis of the disease. The proposed research is capable of measuring the health parameters of patients automatically in a very cost-effective manner with less false alarm rate. Therefore, authors have tested and validated results with the direct measured results using digital thermometers and digital Blood pressure (BP) inflators. The Internet of Things could be considered as a game changer for the healthcare industry. It is improving healthcare day by day by enhancing capabilities, 
reducing costs and continuous vigorous patient monitoring [2]. Through our proposed gadget real time accurate data can be achieved in a very cost-effective manner. This proposed research explains the importance and significance of measuring patient vitals automatically via wearable gadget which has been deployed with pulse sensor and temperature sensor. Gadget also contains RFID that is to be scanned at entrance and exits so that the patient location can be tacked and recorded. Database is maintained for the patient health monitoring. On the basis of database, the doctors can predict and prescribe the further treatment of the patient as well. This research can help to reduce the engagement of nursing staff in measuring patient health parameters manually. The Intensive care units (ICUs) are well equipped with latest machineries but they are for the serious patients and can not be considered as a cost-effective solution as their charges per day are very high. Therefore, a cost-effective solution has been proposed that may be used very easily. Cellular phones are not permitted in the hospitals and person to person communication consumes a lot of time that also has been minimized by using RFID communication. An alert to the main desktop application is also generated for the presence of abnormal and any irregular observation. Radio Frequency Identification is the topmost valuable communication method in the IoT environment as it can be regarded easier to document sensitive data as it is secure, wireless data transmission and track things in surroundings. RFID tag that resides inside the watch is inquired by the RFID receiver, each tag has an exclusive and distinctive identity. When the patient walks from one department to another department he/she only needs to scan their watch in front of the reader and his location will be updated on the database so it will be trouble free for the staff to notify the attendee of a patient from application instead of searching manually in their records.

\section{RECENT TRENDS}

In 2005 Wolkerstorfer initiated the research of internet of things and Elliptic Curve Cryptography [3]. Radio frequency tags actually works as a counter and sense the mutual knowledge to identify, classify and track [4-6]. In Xu et al. [7], the adequate designing of various applications of Internet of Things and Smart devices were represented. Several approaches have been carried out by using RFID-based designs to enhance the patient medical care and safety and to minimize the mistakes [8]. Hippocratic database which authorize activities to follow the privacy and secrecy rules and regulations for health parameters information were introduced by Agrawal and Johnson in 2007 [9]. Several approaches have been carried out to mitigate the false alarm rate like fuzzy logic, Kalman filtering, extended Kalman filtering (EKF), adaptive filtering, Adaptive neuro fuzzy interference system (ANFIS) and Particle Swarm Optimization (PSO) [10]. Particle swarm optimization has been applied to reduce the amount of the false alarm rate. Actually, the outputs from the transducers which have been attached to the wrist gadget are compared with the standard pre-defined limits and any unevenness is reported to the concerned station and location of the patient is also updated using GPS [11]. The collection of data of the patients usually known as electronic medical record (EMR) from various online hospital management systems have been discussed in several research papers from different aspects like security [12, 13], clinical staff management, performance judgment $[14,15]$ and its applications with the RFID [16]. To update the latest patient electronic medical record system must be capable to exchange and access with miscellaneous systems [17], therefore agentbased hybrid algorithm was designed [17]. Extensive researches have been made for the structural health monitoring by RFID [18]. Radio frequency identification (RFID) provides a unique electronic identity for the recognition. RFID is a vigor system having the capability to store and retrieve the data by showing its unique ID. The retrieved information is associated with RFIF tags [19]. Flexibility in electrical, electronic and communication with advanced computational resources including microelectromechanical systems (MEMS) have enabled advance work on body sensor networks (BSNs) that estimate, observe, evaluate and the body signals to discriminate the health disorders [20].

\section{PROBLEM STATEMENT}

There are numerous inventions based on RFID and tracking System. It is very time taking and complex to maintain and record the patient health parameters data manually. The regular practice requires more man power as nursing staff is engaged to measure the patient's vitals periodically. To locate a patient manually it is not possible to identify his or location without searching him. Real-time data transmission is not possible. Measurements and observations observed by the nursing staff contain some human error as well caused by the personal error. Instrumentation and measurement always introduce false alarms especially sensors generate false alarms [1, 20]. High ratio of false alarm leads towards the wrong measurements which may cause several casualties in hospitals. Up to $86 \%$ fake alerts have been observed and recorded that leads towards the negligence of the patient and doctors as well [22]. 


\section{MATERIALS AND METHODS}

\subsection{Main Architecture}

Figure 1 explains the fundamental architecture of the proposed research that how data is transmitted to the RFID receivers and then stored in the desktop application data based (Java Bases).

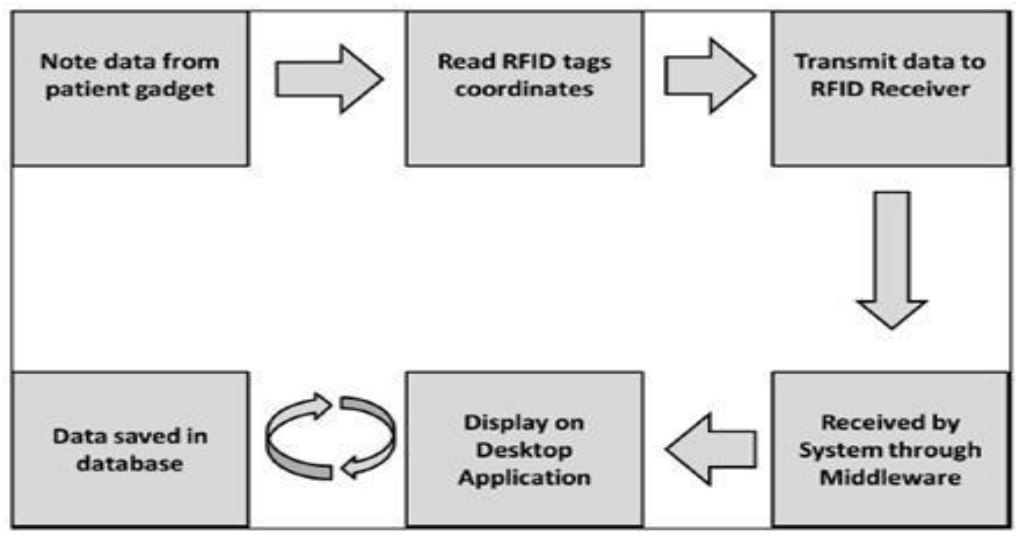

Figure 1. Main architecture

\subsection{Hardware Components}

Figure 2 represents the hardware design that depicts leather watchstrap comprised of battery, RFID tag, Bluetooth module and the microcontroller inside the watch. Two sensors were deployed on the watch that is temperature sensor and the pulse sensor on each side of the strap.



Figure 2. Hardware components

Figure 3 shows the hardware fabricated final model that is easily wearable on the wrist. Design of the gadget is like a wrist watch. The proposed gadget is capable of measuring the pulse rate (cardiac arrhythmias) and body temperature. These crucial parameters are transferred to the hospital database system. 
Privilege of this proposed research is to comfort hospital's most engaged nursing staff for measuring these vitals periodically. Once the data is stored into the database it can be viewed on the desktop application integrated with the watch. Along with the body essentials, patient's location can also be tracked by this tool using RFID.

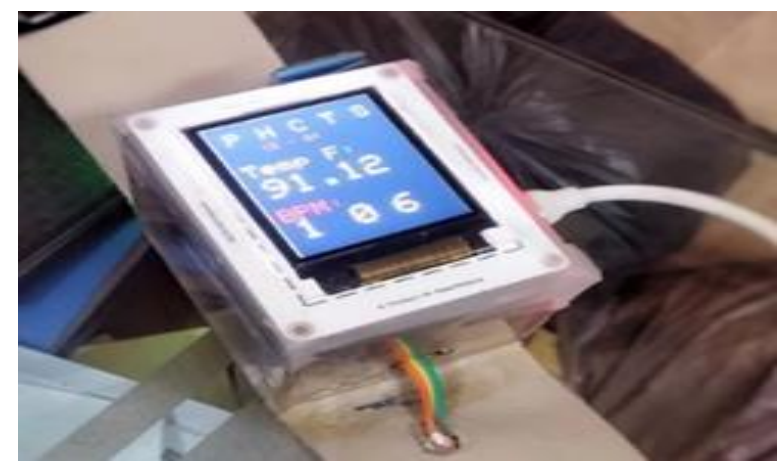

Figure 3. Hardware model

\subsection{Software Application}

Main software application for the database and graphical user interface was programmed on Java. Software has the basic capabilities like staff monitoring, patient tracking, patient identification, health paramter monitoring and presence of patients. Sensors reading are delivered to the system via bluetooth module.

Figure 4 demonstrates the graphical user interface of the software application. The GUI is capable of showing the patient historical record of patient health and bio data of patient.

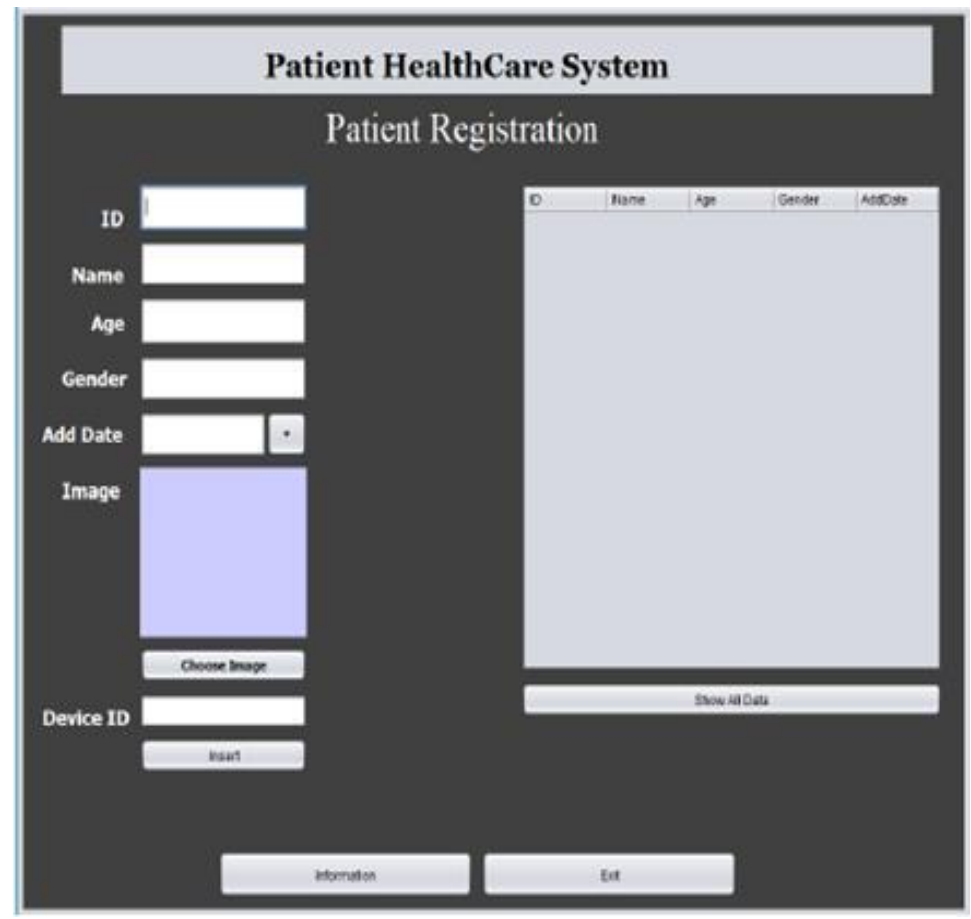

Figure 4. Graphical user interface

Figure 5 explains the basic software architecture step wise process. It shows the tracking process by RFID as patients can be checked at entrance and exits and it will be logged into the system as well. The database can be constructed using RFID like patient name, health history and doctor's detail. 


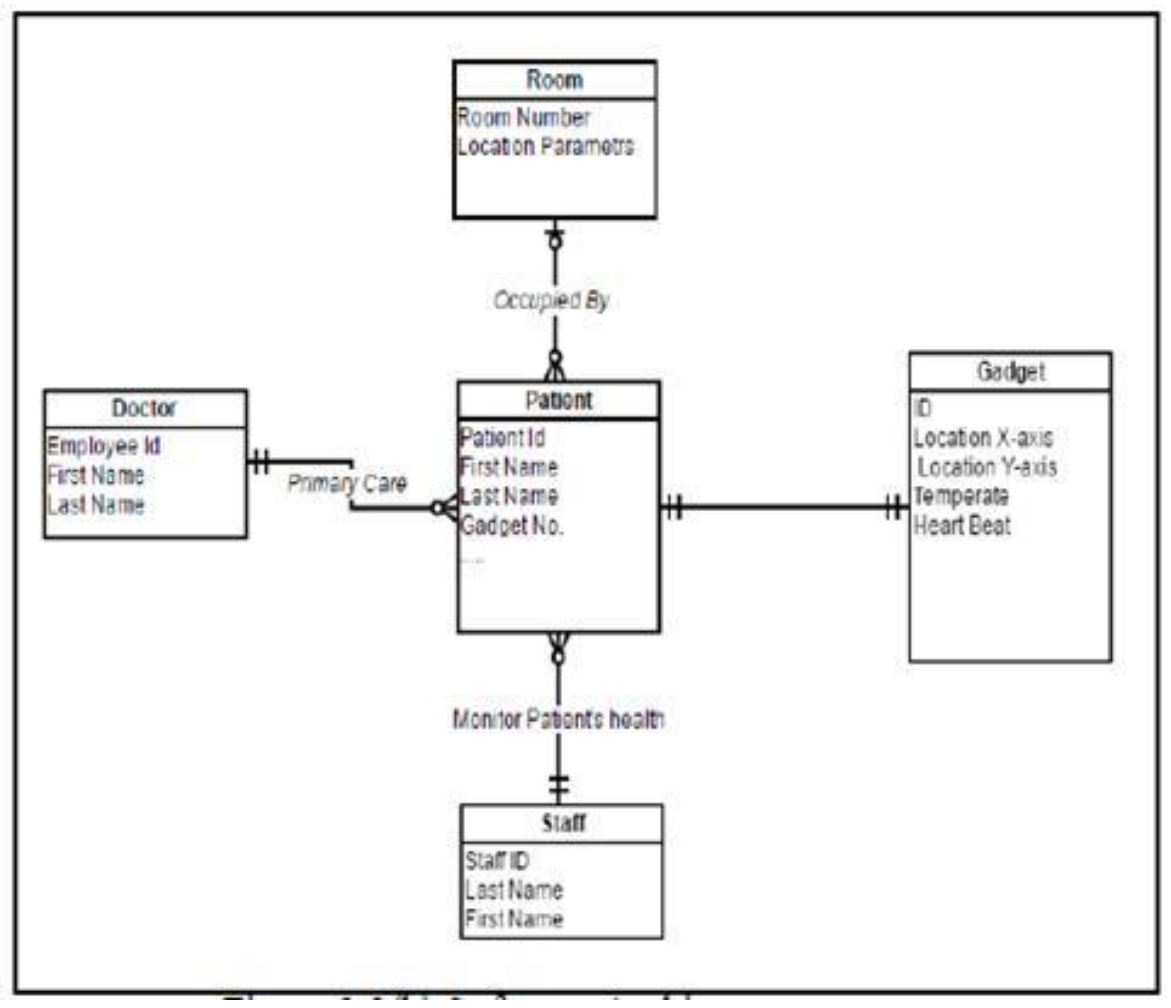

Figure 5. Software architecture

\subsection{Particle Swarm Optimization}

Freshly a latest computational approach was proposed for optimization problem as it has a very less convergence time [21]. Data values were optimized by the PSO to achieve better accuracy. Each particle is described by its position and velocity. Approximate five hundred iterations have been used. PSO initialization has been started.

$$
x(i, j)=x(i, j)+v(i, j)
$$

New position can be found out by using (1)

$\mathrm{x}=\mathrm{x} 0 ; \%$ initial population

$v=0.1 \times x 0$; initial velocity

pbest $=\mathrm{x} 0$; initial pbest

gbest $=\mathrm{x} 0($ index $0,:)$; initial gbest

$$
v(i, j)=w \times v(i, j)+c 1 \times \operatorname{rand} \times(\operatorname{pbest}(i, j)-x(i, j)+c 2 \times \operatorname{rand} \times(\operatorname{gbest}(1, j)-x(i, j))
$$

$\mathrm{c} 1=1.5$

$\mathrm{c} 2=2.5$;

PSO velocity can be updated by using (2)

Best position of the particle and fitness will be estimated using the following code

for $\mathrm{i}=1$ : pop

if $\mathrm{f}(\mathrm{i}, 1)<\mathrm{fO}(\mathrm{i}, 1)$

pbest(i,:) $=\mathrm{x}(\mathrm{i},:)$;

fO $(\mathrm{i}, 1)=\mathrm{f}(\mathrm{i}, 1)$;

end

$$
\text { gbest }_{k}(t)=\text { best }\left\{\text { pbest }_{k}(t)\right\}_{k=1}^{k}
$$

Global best position that will be adapted and used will be estimated by using (3). 


\section{IMPLEMENTATION AND EXECUTION} required.

To properly execute and implement the research idea successfully following components were

a) Microduino Core

b) Temperature Sensor LM 35

c) Pulse Sensor

d) Bluetooth Module HC-05

e) RFID tag

f) RFID Receiver

g) Lithium Polymer Battery

Figure 6 shows the flow along the hardware module. The system validates the gadget at the initialization of device which is given to the patient.

Body vitals are estimated by both of the sensors respectively and sent to the system via Bluetooth. Body vitals are sent continuously according to a predefined time in hardware coding of Microduino. This process runs in the cycle within hardware until the watch is disabled by administrator or loose contact with the patient body.

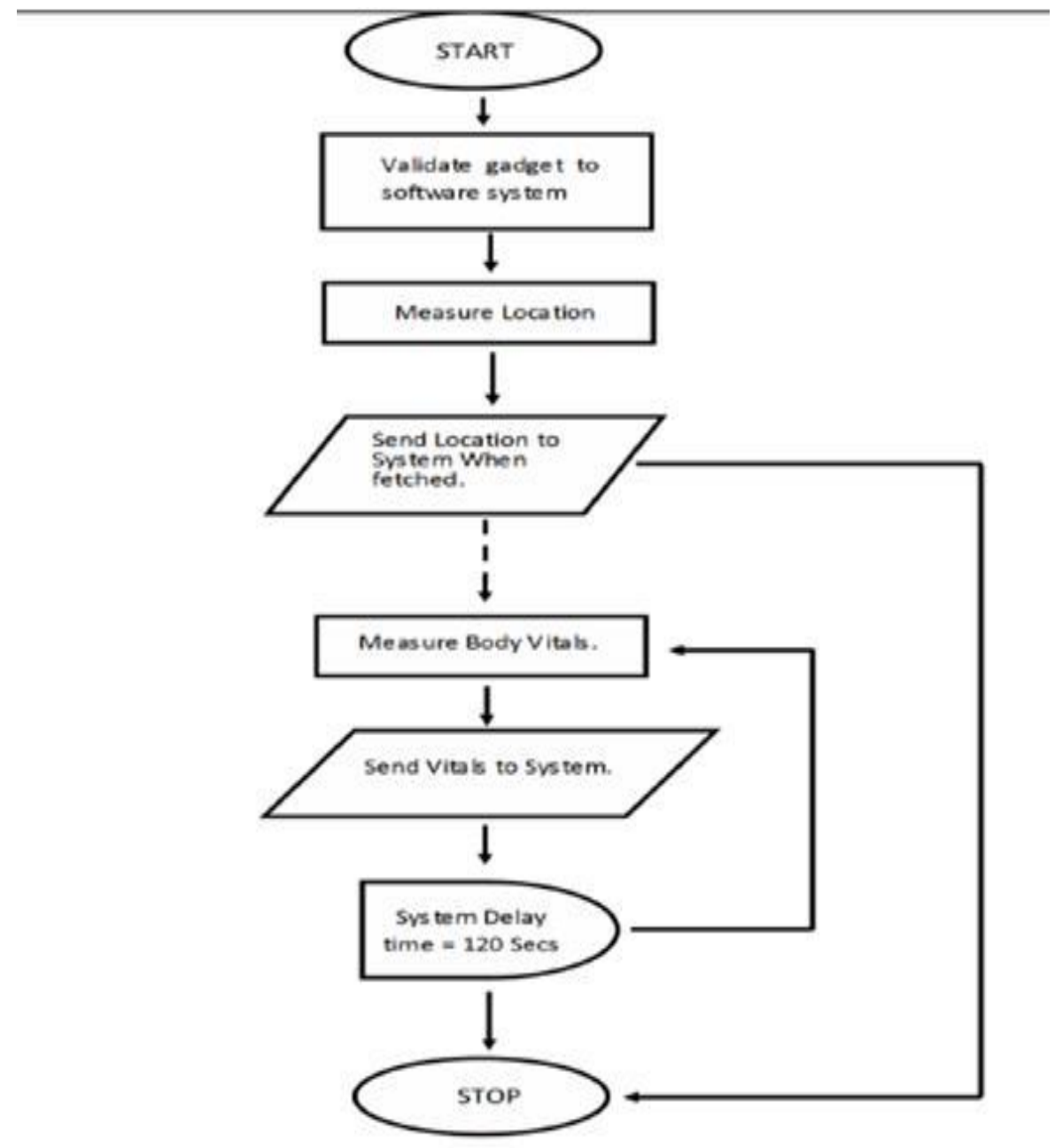

Figure 6. Flow diagram

Figure 7 shows the schematic diagram that has been used to construct the circuitry for the data collection of health parameters. In this schematic you can see that temperature sensor and pulse rate sensor have been attached and TFT has also been interfaced with the microduino. 


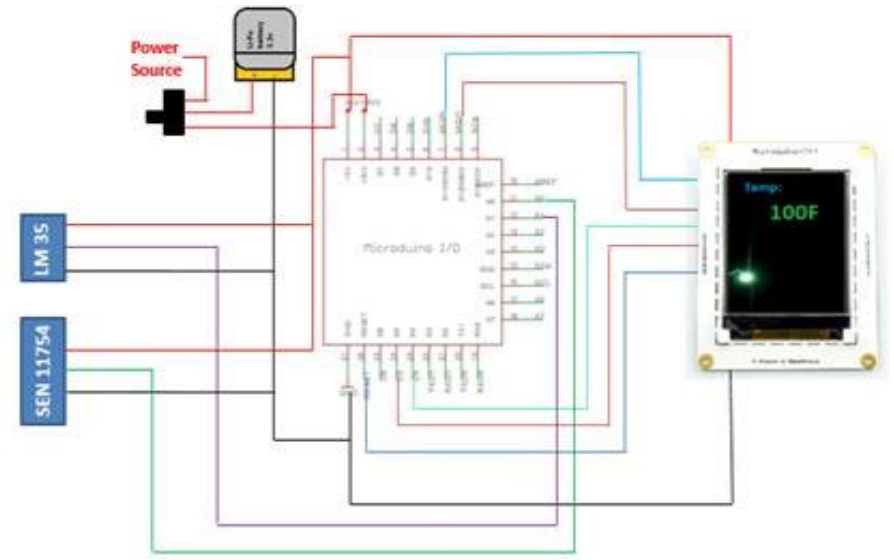

Figure 7. Schematic diagram of experimental setup

\section{TESTING AND VALIDATION}

\subsection{Cardiac Arrhythmias Analysis and Body Temperature Comparison}

Figure 8 demonstrates the comparative analysis of digital BP meter and our proposed gadget on hourly basis. Blue line shows the Digital BP inflator readings and orange one would be for the proposed RFID based gadget. Figure 9 represents the comparative analysis of digital thermometer meter and our proposed gadget on hourly basis. Blue line shows the Digital thermometer readings and orange one would be for the proposed RFID based gadget.

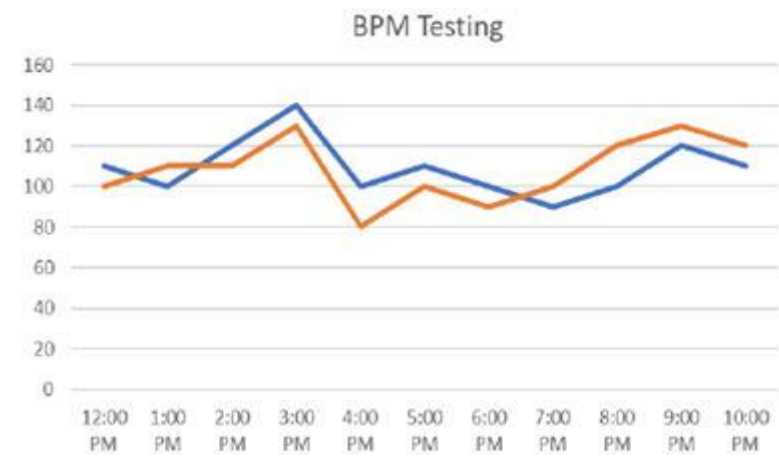

Figure 8. Digital BP vs Gadget

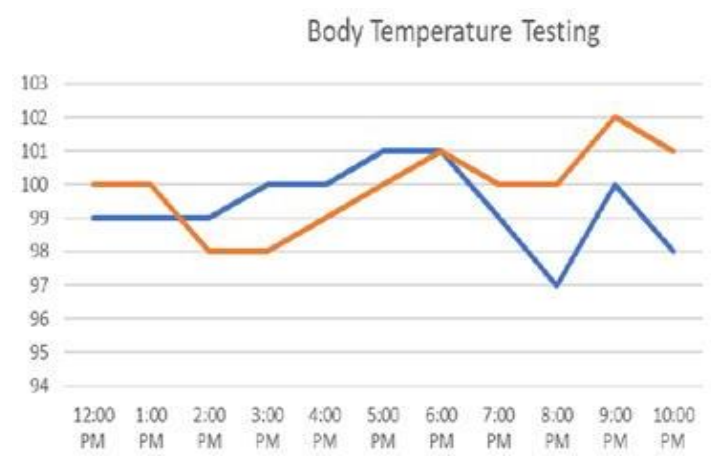

Figure 9. Digital Thermometer vs Gadget

\section{RESULTS AND DISCUSSION}

Table 1 Shows the comparative analysis of digital BP Machine, gadget and the algorithm PSO. There is a difference between them as PSO converge the best value and give the best optimum value based on the training data set.

Table 1. Comparative Analysis of Pulse Rate, Gadget and PSO.

\begin{tabular}{cccc}
\hline Time Interval & Digital BP Machine & Gadget & PSO output \\
\hline 12:00 PM & 110 & 100 & 110 \\
1:00 PM & 100 & 110 & 105 \\
2:00 PM & 120 & 110 & 120 \\
3:00 PM & 140 & 130 & 135 \\
4:00 PM & 100 & 80 & 90 \\
5:00 PM & 110 & 100 & 110 \\
6:00 PM & 100 & 90 & 100 \\
7:00 PM & 90 & 100 & 80 \\
8:00 PM & 100 & 120 & 110 \\
9:00 PM & 120 & 130 & 120 \\
10:00 PM & 110 & 120 & 110 \\
\hline
\end{tabular}




\subsection{Blood Pressure Analysis}

Figure 10 represents the comparative analysis of PSO applied results with the gadget and digital BP inflator results. Red line graph is indicating the PSO output. Green line graph is representing the values of digital BP inflator machine measurements and blue line graph demonstrated the gadget values. Hence it can be concluded that false alarm ratio has been minimized by using PSO.

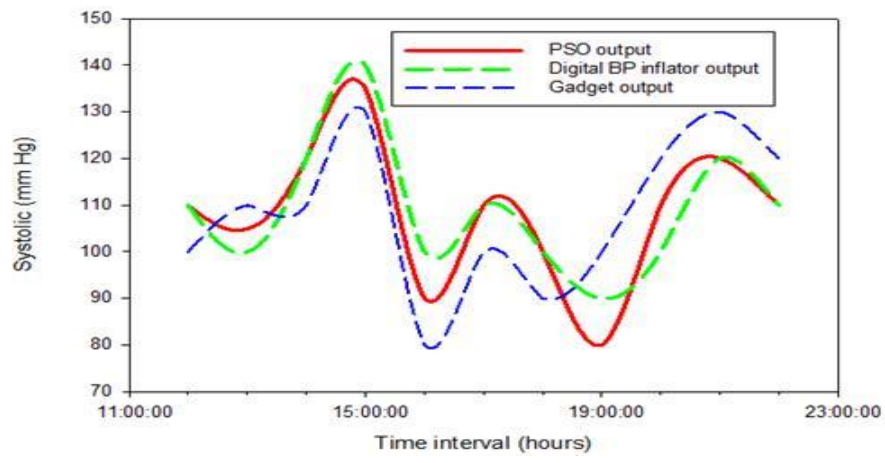

Figure 10. PSO applied results analysis

\subsection{Body Temperature Analysis}

Figure 11 exhibits the hourly investigation of the body temperature by using gadget, digital thermometer and PSO applied results. Difference between two instruments can be observed and can be acknowledged as false alarm. It has been minimized by using the PSO. It can be concluded from the figure that false alarm rate has been further minimized by using PSO. Gadget output is very close to the PSO output and digital thermometer contains some false alarms which have been minimized. Table 2 demonstrated the experimental analysis of digital thermometer, gadget and PSO. These readings have been recorded on hourly basis.

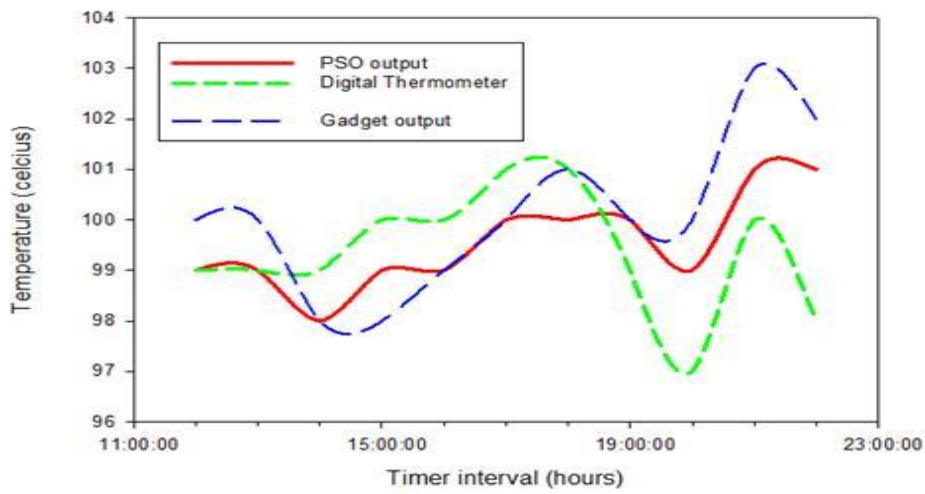

Figure 11. Gadget measurements vs digital thermometer

Table 2. Comparative Analysis of Digital Thermometer, Gadget and PSO.

\begin{tabular}{cccc}
\hline Time Interval & Digital Thermometer & Gadget & PSO output \\
\hline 12:00 PM & 99 & 100 & 99 \\
1:00 PM & 99 & 100 & 99 \\
2:00 PM & 99 & 98 & 98 \\
3:00 PM & 100 & 98 & 99 \\
4:00 PM & 100 & 99 & 99 \\
5:00 PM & 101 & 100 & 100 \\
6:00 PM & 101 & 101 & 100 \\
7:00 PM & 99 & 100 & 100 \\
8:00 PM & 97 & 100 & 99 \\
9:00 PM & 100 & 103 & 101 \\
10:00 PM & 98 & 102 & 101 \\
\hline
\end{tabular}




\section{CONCLUSION AND FUTURE WORK}

In this study it has been analyzed that proposed research performed very well for the data transmission and tracking of the patients and it can be regarded as a cost effective and accurate solution for the database of electronic medical records. Bluetooth feature has also been used as a backup of RFID for the data transmission. RFID is being used for tracking and security purpose at the entrance at exits but Bluetooth technology is being utilized for the periodically and repetitive transmission of body vitals data. Furthermore, it has been suggested that many other several sensors may be added to collect the data for more health parameters like blood pressure (systolic, diastolic), glucose levels, electrocardiography and some other body vitals. Sensors produce some false alarms which have been reduced by using particle swarm optimization. In future some other optimization algorithms may be applied to reduce the false alarms accurately and precisely. Future readings may also be predicted on the basis of the data log available and stored at the electronic medical record (EMR) database.

\section{REFERENCES}

[1] Talha Ahmed Khan, Muhammad Alam, Kushsairy Kadir, Zeeshan Shahid and M. S. Mazliham, "FALSE ALARM Reduction For The Cardiac Arryhthmias: Ai Based Comparative Analysis", Vol-5 2017, Journal of Engineering and Technology", Universiti Kuala lumpur, Kuala Lumpur, Malaysia

[2] Jisha S and M. Philip, "Rfid based security platform for internet of things in health care environment," 2016 Online International Conference on Green Engineering and Technologies (IC-GET), Coimbatore, 2016, pp. 1-3.

[3] J. Wolkerstorfer, "Is elliptic-curve cryptography suitable to secure RFID tags?, ” in Proc. Workshop RFID LightWeight Cryptogr., 2005. K. Elissa, "Title of paper if known," unpublished.

[4] Ullah, Kaleem, Munam Ali Shah, and Sijing Zhang. "Effective ways to use Internet of Things in the field of medical and smart health care", 2016 International Conference on Intelligent systems Engineering (ICISE),2016.

[5] J. Jin, J. Gubbi, S. Marusic, and M. Palaniswami, "An information framework for creating a smart city through Internet of Things," IEEE Internet of Things Journal, vo1. 1, pp. 112-121, 2014

[6] S. F. Khan, "Health care monitoring system in Internet of Things (IoT) by using RFID," 2017 6th International Conference on Industrial Technology and Management (ICITM), Cambridge, 2017.

[7] 1.. Xu, 1.. Rongxing, 1.. Xiaohui, S. Xuemin, C. Jiming, and 1.. Xiaodong, "Smart community: an internet of things application," Communications Magazine, IEEE, vo1. 49, pp. 68-75,2011.

[8] K. H. Yeh, N. W. Lo and C. Wang, "A Patient Privacy-Aware E-health System Based on Passive RFID," 2012 9th International Conference on Ubiquitous Intelligence and Computing and 9th International Conference on Autonomic and Trusted Computing, Fukuoka, 2012, pp. 967-972.

[9] R. Agrawal, C. Johnson, "Securing Electronic Health Records without Impeding the Flow of Information," International Journal of Medical Informatics, vol.76, pp.471-479, 2007.

[10] T. A. Khan, M. Alam, Z. Shahid and M. M. Suud, "Prior investigation for flash floods and hurricanes, concise capsulization of hydrological technologies and instrumentation: A survey," 2017 IEEE 3rd International Conference on Engineering Technologies and Social Sciences (ICETSS), Bangkok, 2017, pp. 1-6.

[11] C. Chellaswamy, L. Balaji, A. Vanathi and L. Saravanan, "IoT based rail track health monitoring and information system," 2017 International conference on Microelectronic Devices, Circuits and Systems (ICMDCS), Vellore, 2017, pp. 1-6.

[12] T.L. Chen, Y.F. Chung, F.Y.S. Lin.: Deployment of secure mobile agents for Medical Information Systems. Springer Science Business Media, LLC 2011

[13] H. Idrissi, A. Revel, E. M. Souidi, Security of Mobile Agent Platforms using RBAC based on Dynamic Role Assignment, International Journal of Security and Its Applications, 2016

[14] K. Miller, G. Mansingh, Comparing the Use of Mobile Intelligent Agents vs Client Server Approach in a Distributed Mobile Health Application, Journal of Computers, Volume 10, No 6, November 2015

[15] Y. El-Gamal, K. El-Gazzar, M. Saeb.: A Comparative Performance Evaluation Model of Mobile Agent versus Remote Method Invocation for Information Retrieval. World Academy of Science, ET 27, 2007

[16] C.J. Su, S.C. Shih: Building Distributed E-Healthcare for Elderly Using RFID and Multi-Agent. International Journal of Engineering Business Management, Vol. 3, No. 1 (2011), pp. 16-26

[17] F. G. Belciug and C. E. Turcu, "Hybrid agent based algorithm for an efficient RFID-based health information system," 2017 E-Health and Bioengineering Conference (EHB), Sinaia, 2017, pp.

[18] J. P. Lynch and K. J. Loh, "A summary review of wireless sensors and sensor networks for structural health monitoring," Shock and Vibration Digest, vol. 38, no. 2, pp. 91-130, 2006.277-280.

[19] R. Abrishambaf, A. Akbari, and M. Hashemipour, "Comparison of wireless sensor network and radio frequency identification for the process control of distributed industrial systems, " Proceedings of the Institution of Mechanical Engineers, Part I: Journal of Systems and Control Engineering, p. 0959651813517499, 2014.

[20] L. Mertz, "Convergence Revolution Comes to Wearables: Multiple Advances are Taking Biosensor Networks to the Next Level in Health Care," in IEEE Pulse, vol. 7, no. 1, pp. 13-17, Jan.-Feb. 2016.

[21] T. Khan et al., "Foreign objects debris (FOD) identification: A cost effective investigation of FOD with less false alarm rate," 2017 IEEE 4th International Conference on Smart Instrumentation, Measurement and Application (ICSIMA), Putrajaya, 2017, pp. 1-4. 
[22] J. P. Kelwade and S. S. Salankar, "An optimal structure of multilayer perceptron using particle swarm optimization for the prediction of cardiac arrhythmias," 2016 5th International Conference on Reliability, Infocom Technologies and Optimization (Trends and Future Directions) (ICRITO), Noida, 2016, pp. 426-430

\section{BIOGRAPHIES OF AUTHORS}
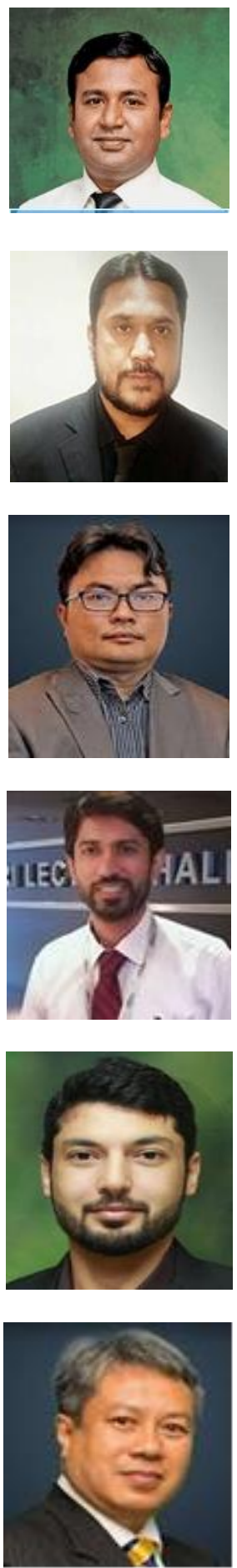

Engr. Talha Ahmed Khan is currently pursuing his $\mathrm{PhD}$ from British Malaysian Institute, Universiti Kuala Lumpur, Malaysia. His education comprises of Bachelor of Engineering in Electronics and Master of Engineering in Telecomunications and serving as an assistant professor in the faculty of Electrical Engineering at UIT. His research areas are artificial intelligence based false alarm reduction in prediction and estimation. He has published upto 18 research papers in well reputed IEEE conferences, Scopus indexed journals and HEC recognized journal.

Prof. Dr. Muhammad Alam is associated with Malaysian Institute of Information Technology, Universiti Kuala Lumpur. He has a vast teaching experience across various universities like KSA, AMA Bahrain, IoBM and ILMA in computer science department with much focus on research. He has published around 180 research papers in well reputed indexed journals and conferences. Currently he is supervising $9 \mathrm{PhD}$ students. His research areas are artificial intelligence, soft computing, loginc design and data mining.

Dr. Kushsairy Kadir currently works as Dean of British Malaysian Institute, Universiti of Kuala Lumpur. He has served as a Director of Research for Innovation, University of Kuala Lumpur. His current project is 'Development of Robots for Assisted Recovery and Rehabilitation'. He has published several research publications.

Engr. M. Junaid Tahir is working as Reseach assistant at British Malaysian Institute, Universiti Kuala Lumpur, Malaysia. He has worked in the engineering faculty of University of Lahore. His research areas are artificial intelligence and Power Electronics He has published several research papers in well reputed IEEE conferences, Scopus indexed journals and HEC recognized journal.

Engr. Dr. Zeeshan Shahid has a PhD and MSc degrees in Electrical and Electronics Engineering from International Islamic University Malaysia. He obtained his B.E from Usman Institute of Technology (UIT). He has published number of research articles in high quality international scientific journals and conference proceedings. He has numerous years experience in industrial and academic field. His research interest is in power engineering specialized in grid-tied inverters, multi-level inverters, DC-DC converters, Integration of renewable energy sources (RES) with utility grids and Power quality improvement.

Prof. Dato' Dr. Mazliham Mohd Su'ud, President, UniKL DSAP, SAP PhD in Computational Intelligence \& Decision, University De La Rochelle, France Post Master Degree in Electronics, University De Montpellier II France Master in Electronics Electrotechnics and Automation, University De Montpellier II, France Bachelor in Electronics Electrotechnics and Automation, University De Montpellier II France Diploma in Science, University De Montpellier II, France. He has vast experience of publishing in high quality international scientific journals and conference proceedings. He has numerous years experience in industrial and academic field. 